\title{
Distribuição espacial dos polos regionais do Cederj: uma análise estatística
}

\author{
Keila Mara Cassiano ${ }^{a}$ \\ Fátima Kzam Damaceno de Lacerda ${ }^{b}$ \\ Carlos Eduardo Bielschowsky c \\ Masako Oya Masuda d
}

\section{Resumo}

O presente trabalho tem como objetivo avaliar a abrangência geográfica da oferta de cursos superiores através da educação a distância pelo Consórcio Cederj no Estado do Rio de Janeiro. Trata-se de um estudo censitário, incluindo todos os alunos ativos dos cursos de graduação, em abril de 2012. Os dados referentes ao número de alunos e locais de residência foram obtidos e, posteriormente, analisados pelo programa SPSS - Statistical Package for the Social Sciences. Foram calculados os Índices do Número de Alunos para Cada 1.000 Habitantes (IACMH) e de Alunos para Cada 1.000 Domicílios (IACMD), baseados nos dados disponibilizados pelo IBGE - Instituto Brasileiro de Geografia e Estatística, 2010. As análises foram feitas por município e por mesorregião do Estado. A distância entre residência e polo, para cada aluno, foi estimada através do Google Maps. Os resultados indicam que a missão inicial do Cederj, de oferecer ensino público e gratuito em regiões não atendidas, ou pouco atendidas, pelas instituições públicas de Ensino Superior, tem sido adequadamente implementada.

Palavras-chave: Educação a distância. Democratização de acesso ao Ensino Superior. Polo de apoio presencial.

\footnotetext{
a Universidade Federal Fluminense - UFF, Departamento de Estatística. Niterói, Rio de Janeiro, Brasil.

b Universidade do Estado do Rio de Janeiro - UERJ, Instituto de Química, COPEI/SR-1. Rio de Janeiro, Rio de Janeiro, Brasil.

c Fundação Centro de Ciências e Educação Superior a Distância - CECIERJ. Rio de Janeiro, Rio de Janeiro, Brasil. Universidade Federal do Rio de Janeiro - UFRJ. Rio de Janeiro, Rio de Janeiro, Brasil.

d Fundação Centro de Ciências e Educação Superior a Distância - CECIERJ. Rio de Janeiro, Rio de Janeiro, Brasil.
} 


\section{Introdução}

O Centro de Educação Superior a Distância do Estado do Rio de Janeiro, Consórcio Cederj, foi iniciado em janeiro de 2000, com a assinatura de um convênio entre o governo do Estado do Rio de Janeiro e seis universidades públicas: Universidade do Estado do Rio de Janeiro (UERJ), Universidade Estadual do Norte Fluminense (UENF), Universidade Federal do Estado do Rio de Janeiro (UNIRIO), Universidade Federal Fluminense (UFF), Universidade Federal do Rio de Janeiro (UFRJ) e Universidade Federal Rural do Rio de Janeiro (UFRRJ). O objetivo foi democratizar o acesso ao Ensino Superior público, gratuito e de qualidade na modalidade de educação a distância, principalmente em locais não atendidos pelo ensino presencial. Esta modalidade foi escolhida para viabilizar a capilarização das ações destas universidades por todo o interior do Estado, uma vez que cinco das seis universidades públicas se localizam na região metropolitana da cidade do Rio de Janeiro.

Um dos elementos importantes na oferta dos cursos de graduação do Consórcio Cederj são os polos regionais, para os quais foi adotado um modelo de financiamento e gestão com a parceria entre entes federativos, modelo inspirado na Universidade Nacional de Educação a Distância da Espanha, a UNED. Inicialmente, esta parceria envolveu o governo do Estado do Rio de Janeiro, através da Fundação Centro de Ciências e Educação Superior a Distância do Estado do Rio de Janeiro (Fundação Cecierj), os municípios que sediam os polos do Cederj e universidades públicas. Em 2006, agregou-se a esta iniciativa o governo federal, através da Universidade Aberta do Brasil (UAB), atualmente sediada na Coordenação de Aperfeiçoamento de Pessoal de Nível Superior (CAPES) (Decreto n ${ }^{\circ} 5.800$ de 08/06/2006, Lei $n^{\circ} 11.502$ de 11/07/2007 e Portaria no 318 de 02/04/2009).

O Consórcio Cederj utiliza um modelo semipresencial de educação a distância, que descrevemos sucintamente na segunda seção deste trabalho. Nesse modelo, os polos regionais desempenham um importante papel para o aluno, especialmente nos dois primeiros anos. A proposta inicial da localização dos polos regionais foi realizada em agosto de 1999, pelo Professor Adilson Gonçalves, através de um estudo técnico que considerou a população dos 92 municípios do Estado do Rio de Janeiro, o número de alunos que terminou no ano anterior o Ensino Médio em cada município, a distância entre os municípios e a existência de estradas conectando-as entre si. Considerou, também, a missão principal do Cederj de oferecer educação superior pública, prioritariamente, onde não se dispunha do Ensino Superior presencial público. Na construção do projeto político-pedagógico do Cederj, previu-se um deslocamento médio do estudante, da sua residência ao polo, inferior a 50 quilômetros (RIO DE JANEIRO, 2000). 
Os quatro primeiros polos foram inaugurados, em 2002, nos municípios de São Fidélis, Itaperuna, Paracambi e Três Rios. Hoje, contamos com uma malha de 33 polos regionais que são apresentados na Figura 1, cobrindo 31 diferentes municípios em 12 carreiras das seis Universidades, acrescida do Centro Federal de Educação Tecnológica Celso Suckow da Fonseca - CEFET/RJ, que se agregou ao consórcio em 2010.

O presente estudo pretende avaliar em que medida a capilarização da oferta de Ensino Superior no Estado do Rio de Janeiro foi alcançada pelo Consórcio Cederj e, em particular, em que medida a atual distribuição dos polos regionais atende todo o Estado, e quais ações precisam ser tomadas para atingir plenamente os objetivos propostos. Para este estudo, um parâmetro importante a ser considerado é o levantamento do local de residência dos alunos dos cursos oferecidos através do Consórcio.

Cabe destacar que os polos não se desenvolveram de forma equânime, principalmente pelo maior ou menor envolvimento das prefeituras municipais. Neste sentido, há polos com infraestrutura que permite a oferta de todas as 12 carreiras e outros onde só é possível oferecer dois cursos. Trata-se de uma questão em constante movimento e que envolve um esforço dos municípios e do governo do Estado. Por exemplo, no ano de 2013, em dois polos, passamos de uma situação de carência de espaço à possibilidade de significativa ampliação dos cursos. Este aspecto influencia na distribuição de alunos no Estado, posto que municípios vizinhos a um polo com pouco desenvolvimento terão, no raio de ação daquele polo, uma reduzida oferta de opções de curso e, portanto, de vagas.

Para o presente estudo, foi realizada uma análise espacial do local de residência do corpo discente do Consórcio Cederj, no mês de abril de 2012 (RIO DE JANEIRO, 2012a,b), sob o ponto de vista descritivo-estatístico. Os dados foram coletados no sistema de registro dos estudantes da Diretoria de Registro Escolar (DRE) do Consórcio.

Descrevemos neste trabalho o modelo de educação semipresencial adotado no Consórcio Cederj, enfatizando a importância dos polos regionais como locais que oferecem aos estudantes múltiplas possibilidades de interação. Foram calculados o Índice do Número de Alunos Cederj para Cada 1.000 Habitantes (IACMH) e o Índice do Número de Alunos do Cederj Para Cada 1.000 Domicílios (IACMD), utilizando-se os dados disponibilizados pelo Instituto Brasileiro de Geografia e Estatística (IBGE). Os resultados são discutidos considerando a distribuição espacial dos polos no Estado do Rio de Janeiro e as distâncias percorridas pelos estudantes que moram em municípios diferentes do município onde se localiza o polo regional em que estão matriculados. 


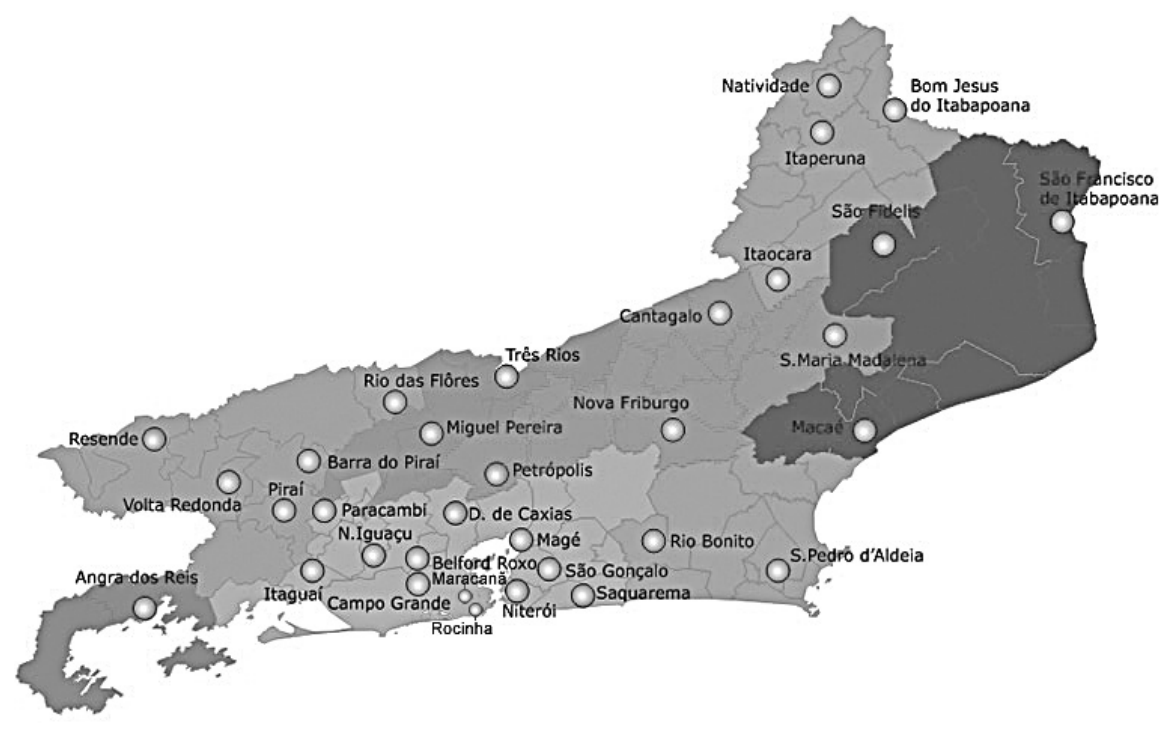

Fonte: RIO DE JANEIRO, 2012.

Figura 1. Localização dos 33 polos regionais do Cederj, em abril de 2012.

\section{O modelo educacional do Consórcio Cederj}

O modelo educacional utilizado no Consórcio Cederj é semipresencial e se baseia em três pilares básicos: material didático impresso de qualidade, interação permanente nos estudos e uma forte avaliação da aprendizagem, como bem aponta Bielschowsky (2006).

O material didático é desenhado especialmente para uso em educação a distância e se caracteriza pelo texto dialógico (o professor conversa com o aluno), uma arquitetura de texto estruturada, e atividades que permitam que o aluno, ao longo de sua leitura possa, no seu ritmo, consolidar a aprendizagem paralelamente a uma autoavaliação ${ }^{1}$. O autor é, na maior parte dos casos, professor da área específica da universidade. Este material é acompanhado de um guia preparado pelo professor que orienta o aluno, sugerindo um cronograma de estudo.

O aluno dispõe de dois ambientes para manter-se conectado e interagindo com os colegas e o corpo docente. Um deles é o polo regional, onde pode haver a

As características de um bom material são descritas por Salgado (2005). Por seu turno, Barreto (2009) relata as etapas envolvidas na produção do material didático impresso do Consórcio Cederj. 
interação face a face com os tutores ${ }^{2}$ presenciais (profissionais de nível superior de área afim do curso e capacitados pelos professores das universidades), com os colegas e, em momentos especiais, com os próprios professores. Particularmente, nos primeiros períodos do curso, o aluno dispõe tipicamente de duas horas semanais de tutoria para cada disciplina. Essas sessões de tutoria presencial, embora não obrigatórias, são muito importantes para apoiar o aluno que vem do curso presencial nos quais, usualmente, tem uma atitude passiva e necessita, na educação a distância, tornar-se o elemento ativo, que busca a aprendizagem (FLINTE; GRENHA; MACEDO, 2008). Para isso, o tutor presencial orienta o aluno no estudo, promove discussão de conteúdos das aulas, coordena grupos de discussão e a realização de atividades experimentais de laboratório e de campo, tira dúvidas dos alunos, além de incentivá-los e apoiá-los diante das dificuldades. No polo regional, o aluno encontra, também, laboratórios didáticos de Informática, Biologia, Física e Química, biblioteca, sala de estudo e acesso livre à internet banda larga, criando, assim, múltiplas possibilidades de interação com os colegas.

O outro ambiente, também essencial para estudo e interação, é o ambiente virtual de aprendizagem (AVA). Este é organizado no sentido de orientar e acompanhar o estudo ao longo da programação de cada disciplina, com atividades, grupos de discussão (síncrona ou assíncrona), uma sala de tutoria virtual, trabalho colaborativo, e-mails, além de material didático em PDF, objetos de aprendizagem multimídia e material complementar. Este espaço representa a sala de aula virtual, conduzida pelo professor com participação dos tutores a distância. Neste ambiente, o aluno pode, também, se comunicar com os colegas, tutores presenciais e a distância que, juntos do professor, constituem o grupo que, além de fornecer os elementos necessários para o estudo, assiste o aluno no seu processo de aprendizagem. O AVA disponibiliza, ainda, todas as informações acadêmicas, como datas e horários das avaliações, regulamentos, regras acadêmicas, entre outras.

Os tutores, presenciais e a distância, são profissionais de nível superior selecionados e capacitados pelos professores, e constituem personagens muito importantes no modelo de docência do Consórcio, pois são os mediadores entre os estudantes e os professores, no sentido lato. Constituem, portanto, o primeiro nível de apoio ao estudante. Os tutores a distância atendem também por telefone, com horários semanais preestabelecidos, na universidade, em adição à sala de tutoria virtual, no AVA mencionado acima.

2 Sobre o papel da tutoria na EAD, destacamos o trabalho de Medeiros et al. (2007). 
Assim, a aprendizagem envolve necessariamente:

- um estudo individual baseado nos materiais didáticos, objetos de aprendizagem e leitura complementar;

- realização de atividades individuais, tanto as contidas no material didático como as propostas para realização no polo e no AVA (dependendo do curso, muitas destas atividades são obrigatórias);

- participação em atividades de grupo no polo e no AVA;

- consulta aos tutores, tanto no polo como por telefone, e no AVA.

O terceiro pilar é uma avaliação de aprendizagem de qualidade ${ }^{3}$ e realizada em condições em que, efetivamente, se possa verificar o desenvolvimento das habilidades e competências previstas nos projetos pedagógicos, e se os níveis requeridos foram alcançados, individualmente, pelos estudantes. São duas avaliações presenciais e duas a distância, obrigatórias. Não conseguindo aprovação com estas quatro avaliações, o aluno pode fazer uma terceira avaliação presencial. O peso das notas das avaliações a distância é de $20 \%$ e das avaliações presenciais, de $80 \%$, na grande maioria das disciplinas.

Podemos então afirmar que, no modelo educacional proposto pelo Cederj, o polo regional, ou polo de apoio presencial, é mais do que uma referência física para que os estudantes possam realizar atividades presenciais, como aulas de laboratório, avaliações, tutoria presencial, trabalhos em grupo: "na realidade, o polo é uma extensão da universidade" (LACERDA, 2012, p. 89).

Face à magnitude dos esforços das universidades públicas na ampliação de suas atividades de ensino, pesquisa e extensão, torna-se necessária a produção de conhecimento que possa contribuir na análise dos resultados já obtidos e na orientação de ações futuras, no que se refere à implantação de novos polos e cursos de graduação semipresenciais. Neste sentido, este estudo pretende oferecer uma contribuição relevante.

\section{Aspectos metodológicos}

Foram utilizados dados primários e secundários para avaliar a distribuição geográfica dos polos regionais e o atendimento aos estudantes dos cursos de graduação semipresenciais oferecidos pelo Consórcio Cederj, em termos da distância entre residência e polo.

Em seus trabalhos, Alonso (2005) e Polak (2009) discutem a importância e as especificidades da avaliação da aprendizagem na educação a distância. 
Os dados referentes ao número de alunos e locais de residência foram obtidos diretamente da base de registros no sistema do DRE - Diretoria de Registro Escolar do Consórcio Cederj, abrangendo todos os estudantes ativos, ou seja, estudantes formalmente inscritos em disciplinas, em abril de 2012. Logo, trata-se de um estudo censitário, não amostral. Além disso, foram utilizados dados demográficos do Estado do Rio de Janeiro, com estatísticas do último Censo de 2010 (IBGE, 2010).

Os dados coletados foram organizados em banco de dados e analisados pelo programa SPSS (Statistical Package for the Social Sciences), versão 13.0, e pelo Microsoft Excel 2007.

A análise descritiva dos dados foi baseada na construção de distribuições de frequências, cálculo de proporções de interesse, do Índice do Número de Alunos Cederj para Cada 1.000 Habitantes e do Índice do Número de Alunos Cederj para Cada 1.000 Domicílios. Tais análises foram feitas por município e por mesorregião do Estado. Adotou-se a definição das mesorregiões geográficas do Estado disponível em http://www.oguiadorio.com.br/mesorregioes-do-rio-de-janeiro. Por esta definição, a composição de cada mesorregião é dada como se segue:

- Mesorregião das Baixadas Litorâneas: composta pelos municípios Maricá, Cachoeiras de Macacu, Rio Bonito, Casimiro de Abreu, Rio das Ostras, Silva Jardim, Araruama, Armação de Búzios, Arraial do Cabo, Cabo Frio, Iguaba Grande, São Pedro da Aldeia, Saquarema;

- Mesorregião do Centro Fluminense: composta pelos municípios Cantagalo, Carmo, Cordeiro, Macuco, Bom Jardim, Duas Barras, Nova Friburgo, Sumidouro, Santa Maria Madalena, São Sebastião do Alto, Trajano de Moraes, Areal, Comendador Levy Gasparian, Paraíba do Sul, Sapucaia e Três Rios;

- Mesorregião Metropolitana do Rio de Janeiro: composta pelos municípios Itaguaí, Mangaratiba, Seropédica, Belford Roxo, Duque de Caxias, Guapimirim, Itaboraí, Japeri, Mesquita, Nilópolis, Niterói, Nova Iguaçu, Queimados, Rio de Janeiro, São Gonçalo, São João de Meriti, Tanguá, Petrópolis, São José do Vale do Rio Preto, Teresópolis, Engenheiro Paulo de Frontin, Mendes, Miguel Pereira, Paracambi, Paty de Alferes, Vassouras;

- Mesorregião do Norte Fluminense: composta pelos municípios Campos dos Goytacazes, Cardoso Moreira, São Fidélis, São Francisco de Itabapoana, São João da Barra, Macaé, Carapebus, Conceição de Macabu, Macaé, Quissamã;

- Mesorregião do Noroeste Fluminense: composta pelos municípios Bom Jesus do Itabapoana, Italva, Itaperuna, Laje do Muriaé, Natividade, Porciúncula, Varre-Sai, Aperibé, Cambuci, Itaocara, Miracema, Santo Antônio de Pádua, São José de Ubá; 
- Mesorregião do Sul Fluminense: composta pelos municípios Angra dos Reis, Paraty, Barra do Piraí, Rio das Flores, Valença, Barra Mansa, Itatiaia, Pinheiral, Piraí, Porto Real, Quatis, Resende, Rio Claro, Volta Redonda.

A distância entre residência e polo, para cada aluno, foi estimada através do Google Maps $^{\circledR}$ e refere-se à distância aproximada, em quilômetros, entre município declarado pelo discente como o de sua residência e o município do polo em que está matriculado. Considerou-se, portanto, nula a distância no caso dos estudantes moradores do mesmo município do polo. As análises foram realizadas baseadas no cálculo das estatísticas mínimo, máximo, média, mediana e percentil 95, e nas medidas de dispersão desvio padrão e coeficiente de variação $(\mathrm{CV})$.

\section{Resultados e discussão}

A Tabela 1 mostra que, no mês de abril de 2012, o Consórcio Cederj tinha 21.699 alunos ativos, dos quais, 94,93\% residentes no Estado do Rio de Janeiro, conforme declaração dos discentes obtida no sistema do DRE. Os demais Estados com maior número de alunos ativos no Consórcio Cederj foram Minas Gerais, com 2,36\% e Espírito Santo, com 1,48\%; seguidos por São Paulo, com $0,75 \%$ do total de alunos. Sendo assim, podemos dizer que quase $100 \%$ dos alunos ativos residiam na região Sudeste e, como pode ser verificado na Tabela 1, havia pelo menos um discente residente em cada uma das regiões do país.

Tabela 1. Distribuição estadual da residência dos alunos ativos do Consórcio Cederj, em abril de 2012.

\begin{tabular}{lccc}
\hline Região & Estado & Frequência & Percentual \\
\hline Centro-Oeste & DF & 7 & 0,03 \\
Nordeste & BA & 1 & 0,00 \\
Norte & PA & 1 & 0,00 \\
Sudeste & ES & 322 & 1,48 \\
& MG & 512 & 2,36 \\
& RJ & 20.598 & 94,93 \\
& SP & 163 & 0,75 \\
Sul & PR & 2 & 0,01 \\
& SC & 2 & 0,01 \\
& Não há informação & 91 & 0,42 \\
& Total de alunos ativos & 21.699 & 100,00 \\
\hline
\end{tabular}

Fonte: RIO DE JANEIRO (2012). 
A Tabela 2 apresenta o número de discentes do Consórcio Cederj que moravam em cada um dos 92 municípios do Estado do Rio de Janeiro, em abril de 2012. O que observamos é que todos os municípios do Estado do Rio de Janeiro apresentavam alunos ativos no Cederj. Com base nas estatísticas do número de habitantes e do número de domicílios, disponibilizadas pelo IBGE, foram estimadas as seguintes estatísticas para cada município: Índice do Número de Alunos Cederj para Cada 1.000 Habitantes e Índice do Número de Alunos Cederj para Cada 1.000 Domicílios . A referida tabela apresenta os dados por ordem decrescente do índice de alunos para cada 1.000 habitantes. No geral, o Consórcio Cederj contava com 20.598 alunos ativos residentes no Estado do Rio de Janeiro, na proporção de 1,29 alunos ativos para cada 1.000 habitantes do Estado e 4,02 alunos ativos para cada 1.000 domicílios do Estado.

Tabela 2. Distribuição municipal dos alunos ativos do Cederj residentes no Estado do Rio de Janeiro, em abril de 2012. Foi utilizada ordem decrescente do IACMH.

\begin{tabular}{|c|c|c|c|}
\hline Município & Alunos Ativos & IACMH & IACMD \\
\hline Itaocara & 189 & 8,25 & 23,65 \\
\hline São Fidélis & 307 & 8,18 & 23,95 \\
\hline Cantagalo & 151 & 7,62 & 24,74 \\
\hline Cordeiro & 146 & 7,16 & 22,42 \\
\hline São Sebastião do Alto & 63 & 7,07 & 22,81 \\
\hline Miguel Pereira & 164 & 6,65 & 19,81 \\
\hline Angra dos Reis & 981 & 5,80 & 18,97 \\
\hline Macuco & 30 & 5,69 & 18,19 \\
\hline Natividade & 85 & 5,64 & 17,11 \\
\hline Rio das Flores & 48 & 5,62 & 19,78 \\
\hline São Francisco de Itabapoana & 226 & 5,46 & 16,74 \\
\hline Piraí & 142 & 5,40 & 17,64 \\
\hline Varre-Sai & 49 & 5,16 & 17,73 \\
\hline Três Rios & 398 & 5,14 & 16,79 \\
\hline Resende & 612 & 5,11 & 16,03 \\
\hline Mendes & 87 & 4,85 & 14,13 \\
\hline Cambuci & 71 & 4,79 & 13,99 \\
\hline Paraíba do Sul & 192 & 4,67 & 15,3 \\
\hline Comendador Levy Gasparian & 38 & 4,64 & 15,31 \\
\hline
\end{tabular}

Continua 


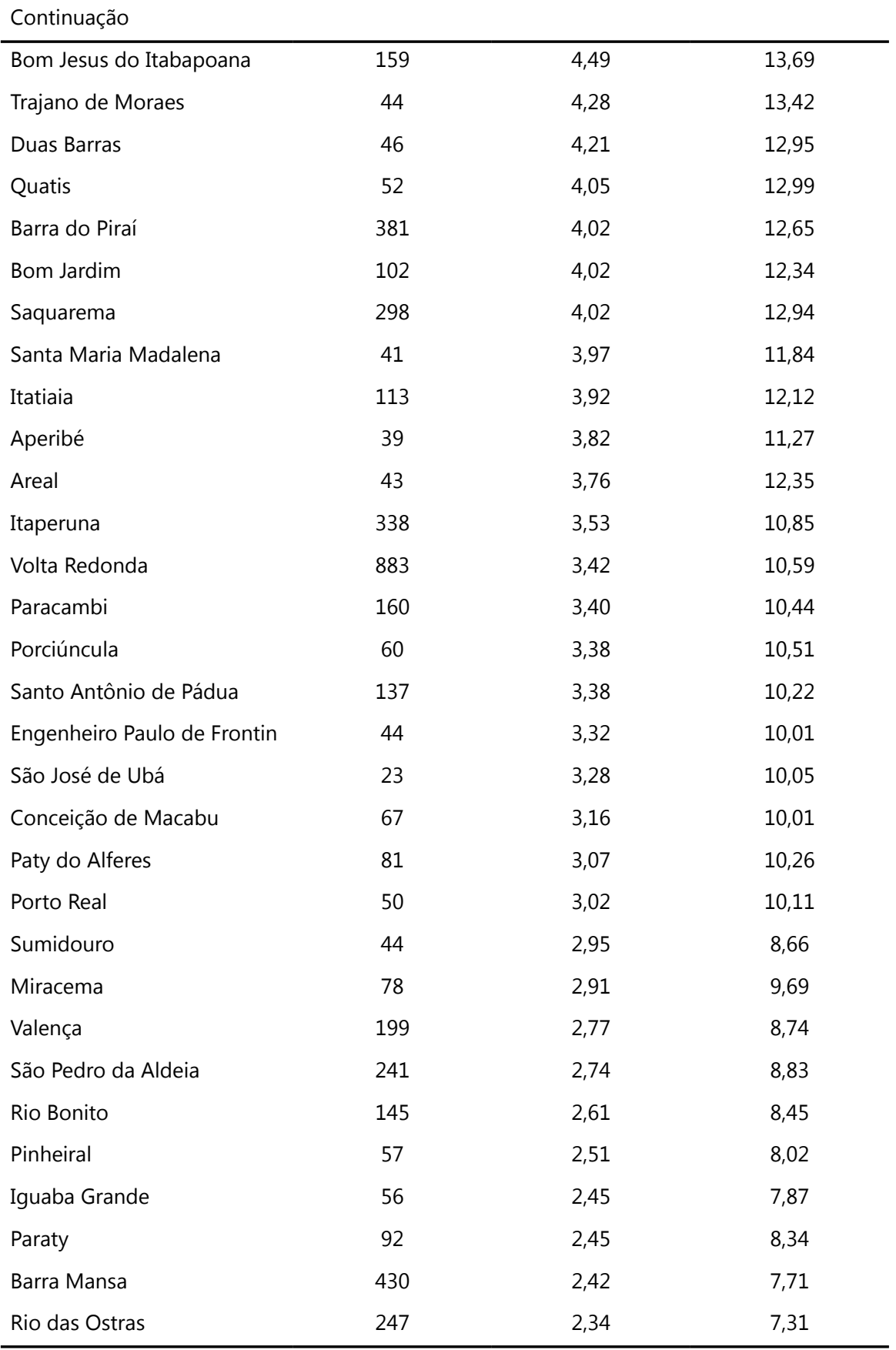

Continua 
Continuação

\begin{tabular}{|c|c|c|c|}
\hline Carmo & 40 & 2,29 & 6,98 \\
\hline Nova Friburgo & 411 & 2,26 & 6,64 \\
\hline Petrópolis & 597 & 2,02 & 6,33 \\
\hline Mangaratiba & 71 & 1,96 & 6,22 \\
\hline Araruama & 211 & 1,88 & 5,98 \\
\hline Silva Jardim & 40 & 1,87 & 5,95 \\
\hline Italva & 26 & 1,85 & 5,44 \\
\hline Seropédica & 141 & 1,80 & 5,93 \\
\hline Cachoeiras de Macacu & 92 & 1,69 & 5,23 \\
\hline Laje do Muriaé & 12 & 1,60 & 4,99 \\
\hline Vassouras & 53 & 1,54 & 4,85 \\
\hline Sapucaia & 26 & 1,49 & 4,74 \\
\hline Casimiro de Abreu & 50 & 1,41 & 4,38 \\
\hline Arraial do Cabo & 38 & 1,37 & 4,28 \\
\hline Maricá & 175 & 1,37 & 4,13 \\
\hline Cardoso Moreira & 17 & 1,36 & 3,97 \\
\hline Magé & 296 & 1,30 & 4,26 \\
\hline Japeri & 123 & 1,29 & 4,46 \\
\hline Geral & 20.598 & 1,29 & 4,02 \\
\hline Macaé & 260 & 1,26 & 4,02 \\
\hline Rio Claro & 21 & 1,21 & 3,89 \\
\hline Cabo Frio & 224 & 1,20 & 3,9 \\
\hline Queimados & 164 & 1,19 & 4,05 \\
\hline Campos dos Goytacazes & 547 & 1,18 & 3,92 \\
\hline Nilópolis & 174 & 1,10 & 3,46 \\
\hline Itaboraí & 237 & 1,09 & 3,42 \\
\hline $\begin{array}{l}\text { São José do Vale do Rio } \\
\text { Preto }\end{array}$ & 22 & 1,09 & 3,38 \\
\hline Mesquita & 178 & 1,06 & 3,44 \\
\hline Niterói & 505 & 1,04 & 3,09 \\
\hline Armação dos Búzios & 27 & 0,98 & 3,02 \\
\hline
\end{tabular}

Continua 


\begin{tabular}{lccc} 
Continuação & \multicolumn{3}{l}{} \\
\hline Itaguaí & 104 & 0,95 & 3,17 \\
Nova Iguaçu & 695 & 0,87 & 2,87 \\
Guapimirim & 41 & 0,80 & 2,62 \\
Tanguá & 23 & 0,75 & 2,39 \\
São Gonçalo & 738 & 0,74 & 2,30 \\
Teresópolis & 115 & 0,70 & 2,17 \\
Rio de Janeiro & 4.338 & 0,69 & 2,08 \\
São João de Meriti & 284 & 0,62 & 1,96 \\
Duque de Caxias & 503 & 0,59 & 1,90 \\
Quissamã & 11 & 0,54 & 1,79 \\
Belford Roxo & 226 & 0,48 & 1,57 \\
Carapebus & 5 & 0,37 & 1,22 \\
São João da Barra & 8 & 0,24 & 0,76 \\
\hline
\end{tabular}

Fontes: RIO DE JANEIRO (2012), IBGE (2010).

Como pode ser visto na Tabela 2, os cinco municípios com maior densidade de alunos no Consórcio Cederj (normalizados pelo número de habitantes) foram os municípios de Itaocara, São Fidélis, Cantagalo, Cordeiro e São Sebastião do Alto. Nestes municípios observou-se que havia mais que sete alunos ativos no Cederj para cada 1.000 habitantes, chegando a 8,25 alunos ativos no Cederj a cada 1.000 habitantes no município de Itaocara.

Por outro lado, 14 dos 92 municípios do Estado do Rio de Janeiro apresentaram índices de número de alunos ativos por 1.000 habitantes inferiores a 1,0. São estes os municípios de Armação dos Búzios, Itaguaí, Nova Iguaçu, Guapimirim, Tanguá, São Gonçalo, Teresópolis, a capital - Rio de Janeiro, São João de Meriti, Duque de Caxias, Quissamã, Belford Roxo, Carapebus e São João da Barra.

Podemos dividir os motivos para esta baixa densidade de alunos nestes municípios em três diferentes categorias:

1. Para oito municípios, este fato é decorrente da estratégia adotada pelo Consórcio em atuar de forma a complementar o ensino presencial público existente. São estes os casos do município do Rio de Janeiro (capital) e municípios vizinhos, tais como São João de Meriti, Nova Iguaçu, Duque 
de Caxias, São Gonçalo e Belford Roxo, que são próximos a cinco das seis Universidades presenciais, bem como nos municípios de São João da Barra, Carapebus e Quissamã, que são próximos a Campos dos Goytacazes, onde se localiza a UENF.

2. O baixo IACMH de Teresópolis pode ser explicado devido ao fato de estar previsto, para este município, um polo presencial ainda não implementado, que também atenderia a Guapimirim, vizinho a Teresópolis.

3. Em outros casos, como dos municípios de Armação dos Búzios, Itaguaí, Guapimirim e Tanguá, o motivo decorre, provavelmente, do baixo desempenho em termos de número de cursos de graduação nos polos que atendem a estes municípios. Este é o caso de Itaguaí, onde dispomos de um polo regional com uma infraestrutura que só permite a oferta de poucos cursos e, sendo uma região de grande densidade populacional, requer uma nova sede que está em estudo. Este também é o caso de Tanguá, vizinho ao município de Rio Bonito, cujo polo regional necessita ampliação para oferta de novos cursos, bem como o município de Armação de Búzios, próximo do polo de São Pedro de Aldeia, que não comporta mais de dois cursos.

Neste sentido, o presente estudo aponta as necessidades de implementação do polo regional de Teresópolis, de ampliação da oferta de cursos no polo de Rio Bonito e Itaguaí, bem como a busca de uma solução para o melhor atendimento dos habitantes dos municípios em torno de São Pedro de Aldeia.

Ao avaliar a distribuição espacial de alunos ativos do Cederj por mesorregião do Estado, exibida na Tabela 3, observou-se que a mesorregião com menor densidade de alunos ativos é a região metropolitana do Rio de Janeiro, com apenas 0,82 alunos a cada 1.000 habitantes. Desta forma, o Cederj atende um maior número relativo de alunos das mesorregiões do Noroeste Fluminense (3,99/1.000 habitantes), do Sul Fluminense (3,82/1.000 habitantes) e do Centro Fluminense (3,77/1.000 habitantes), ou seja, o Cederj atende, em prioridade relativa, regiões distantes da capital. Estes resultados estão em consonância com a missão inicial do Cederj, a de atender a regiões com carência de Ensino Superior público, posto que no Rio de Janeiro as universidades públicas (UERJ, UFRJ, UNIRIO, UFRRJ e UFF) concentravam-se no município do Rio de Janeiro e municípios vizinhos, com apenas alguns campi no interior, à exceção da UENF, localizada na região do Norte Fluminense.

Estes resultados mostram que, para alcançar uma maior densidade de oferta em todas as regiões, será necessário aumentar a oferta na região metropolitana do Rio de Janeiro, bem como na região do Norte Fluminense. 
Tabela 3. Distribuição mesorregional dos alunos ativos do Cederj residentes no Estado do Rio de Janeiro, em abril de 2012.

\begin{tabular}{lccc}
\hline Mesorregião & Alunos Ativos & IACMH & IACMD \\
\hline Baixada Litorânea & 1.844 & 1,96 & 6,21 \\
Centro Fluminense & 1.815 & 3,77 & 11,63 \\
Metropolitana do Rio de Janeiro & 10.164 & 0,82 & 2,56 \\
Noroeste Fluminense & 1.266 & 3,99 & 12,21 \\
Norte Fluminense & 1.448 & 1,70 & 5,52 \\
Sul Fluminense & 4.061 & 3,82 & 12,15 \\
Geral & 20.598 & 1,29 & 4,02 \\
\hline
\end{tabular}

Fontes: RIO DE JANEIRO (2012), IBGE (2010).

O mapa exibido na Figura 2 mostra a localização das regiões e os índices de alunos por 1.000 habitantes das regiões.

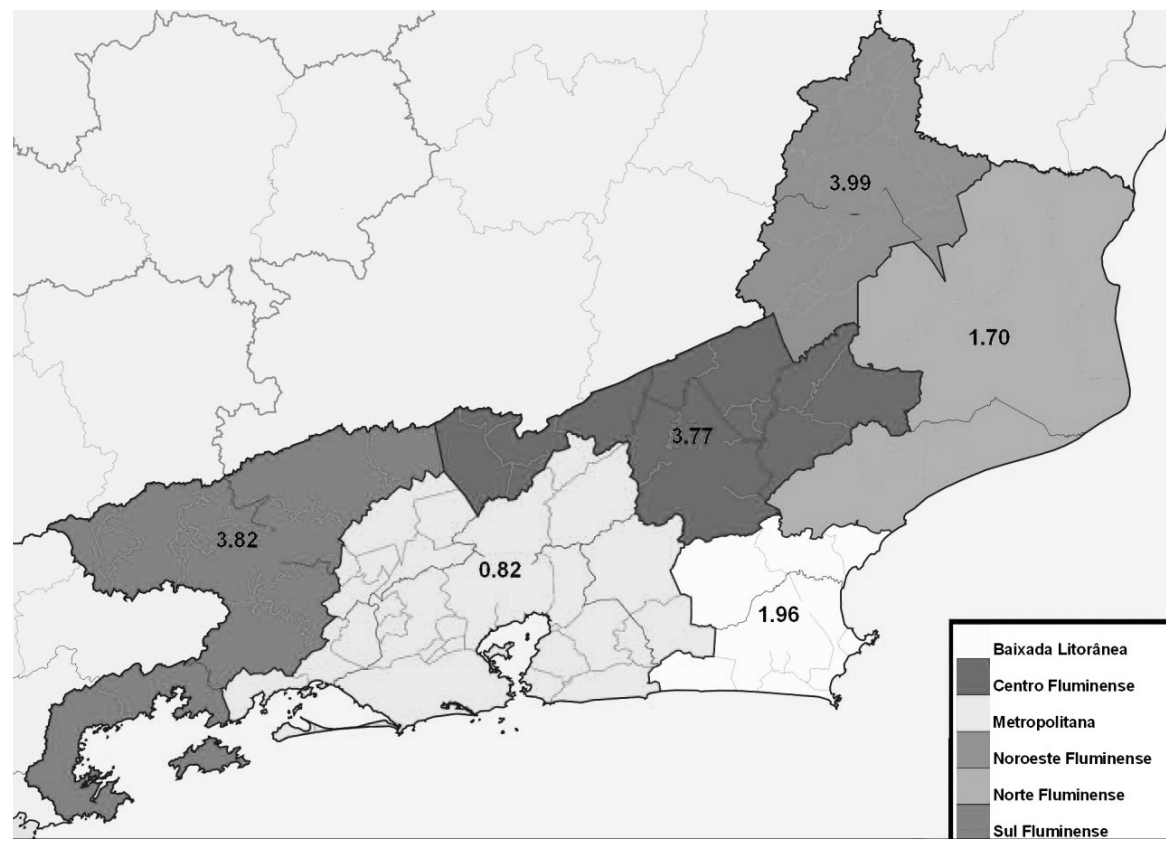

Fontes: RIO DE JANEIRO (2012), IBGE (2010).

Figura 2. Índice de alunos ativos no Cederj por 1.000 habitantes em cada mesorregião do Estado do Rio de Janeiro, em abril de 2012. 
A Tabela 4 apresenta o número de alunos ativos em cada polo, com os percentuais de discentes moradores do mesmo município do polo em ordem decrescente. Os polos com maiores números de alunos ativos foram os polos de Angra dos Reis, Paracambi, Nova Iguaçu, Piraí, Resende, Volta Redonda e Saquarema, todos com mais de 1.000 alunos ativos, enquanto os polos de Rocinha, Santa Maria Madalena e Natividade apresentaram menos de 200 alunos ativos. É importante destacar que o polo Rocinha foi inaugurado em janeiro de 2012 e, portanto, conta apenas com as turmas de primeiro período de seus quatro cursos, enquanto Santa Maria Madalena e Natividade foram criados, inicialmente, como postos vinculados, respectivamente, aos polos de Cantagalo e Itaperuna, com o objetivo de oferecer uma infraestrutura computacional e de atendimento aos alunos, que deveriam se dirigir aos polos para todas as atividades obrigatórias, exceto realização das provas presenciais. Posteriormente, com a normatização da educação a distância pelo MEC - Ministério da Educação, estes postos de atendimento foram transformados em polos, razão pela qual o número de alunos é pequeno.

Em termos gerais, 39,81\% dos discentes ativos do Cederj moram no mesmo município do polo. Os polos da capital, Campo Grande, Rocinha e Maracanã-UERJ, foram os que apresentaram maiores percentuais de alunos residentes no mesmo município do polo, uma vez que mais de $85 \%$ dos discentes declararam morar na capital. Já Paracambi, Piraí, Itaguaí e Rio das Flores são os polos com menores percentuais de alunos residentes no próprio município, com menos de $20 \%$. As frequências de alunos que moram no mesmo município do polo ficaram abaixo do percentual geral, de $39,81 \%$ em 18 polos, como pode ser verificado na Tabela 4 .

Tabela 4. Distribuição por polo dos alunos ativos do Cederj, em abril de 2012, ordenados pelo percentual de alunos moradores no mesmo município do polo.

\begin{tabular}{lcccc}
\hline Polo (no de cursos) & $\begin{array}{c}\text { Número de } \\
\text { alunos } \\
\text { ativos }\end{array}$ & $\begin{array}{c}\text { Percentual } \\
\text { em } \\
\text { relação ao } \\
\text { total }\end{array}$ & $\begin{array}{c}\text { Alunos } \\
\text { moradores } \\
\text { no mesmo } \\
\text { município do } \\
\text { polo }\end{array}$ & $\begin{array}{c}\text { Percentual dos } \\
\text { alunos moradores } \\
\text { no mesmo } \\
\text { município do polo }\end{array}$ \\
\hline Campo Grande (5) & 969 & 4,47 & 863 & 89,06 \\
Rocinha (4) & 181 & 0,83 & 156 & 86,19 \\
Maracanã (1) & 257 & 1,18 & 219 & 85,21 \\
Petrópolis (3) & 725 & 3,34 & 510 & 70,34 \\
Angra Dos Reis (8) & 1.396 & 6,43 & 960 & 68,77 \\
Barra do Piraí (3) & 205 & 0,94 & 135 & 65,85 \\
\hline
\end{tabular}

Continua 


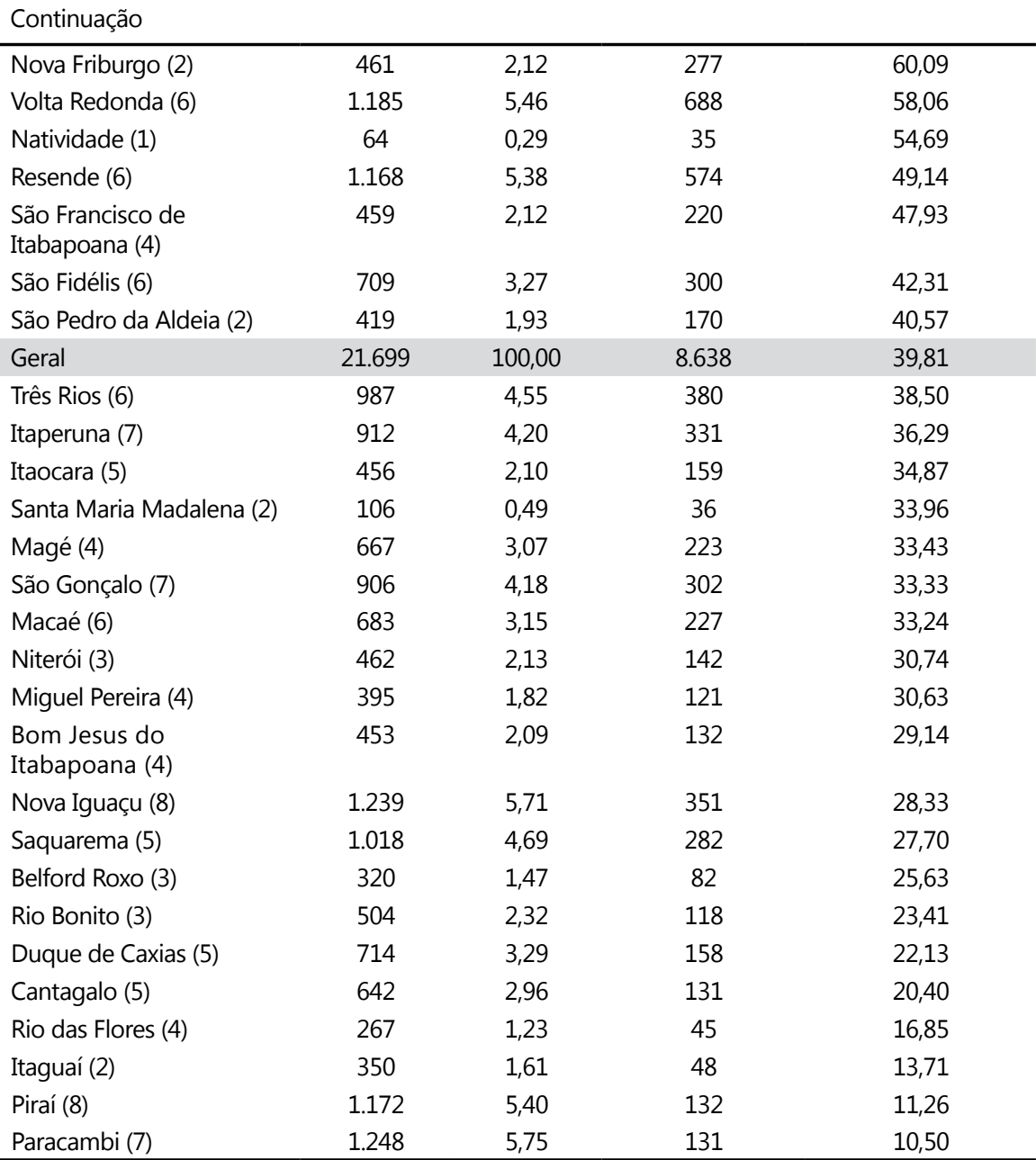

Fonte: RIO DE JANEIRO, 2012.

A Tabela 5 apresenta as estimativas das principais estatísticas de distância percorrida (em quilômetros) pelos discentes que moram em municípios do Estado do Rio de Janeiro diferentes do polo onde estão matriculados. Os dados são ordenados decrescentemente pela estatística mediana. Optou-se por ordenar e dar ênfase à mediana, por ser uma medida central robusta menos afetada pela presença de possíveis outliers resultantes de alunos que moram em municípios atipicamente muito distantes dos polos. Tais outliers contaminam a média, elevando-a significativamente, mas influenciam pouco a mediana. 


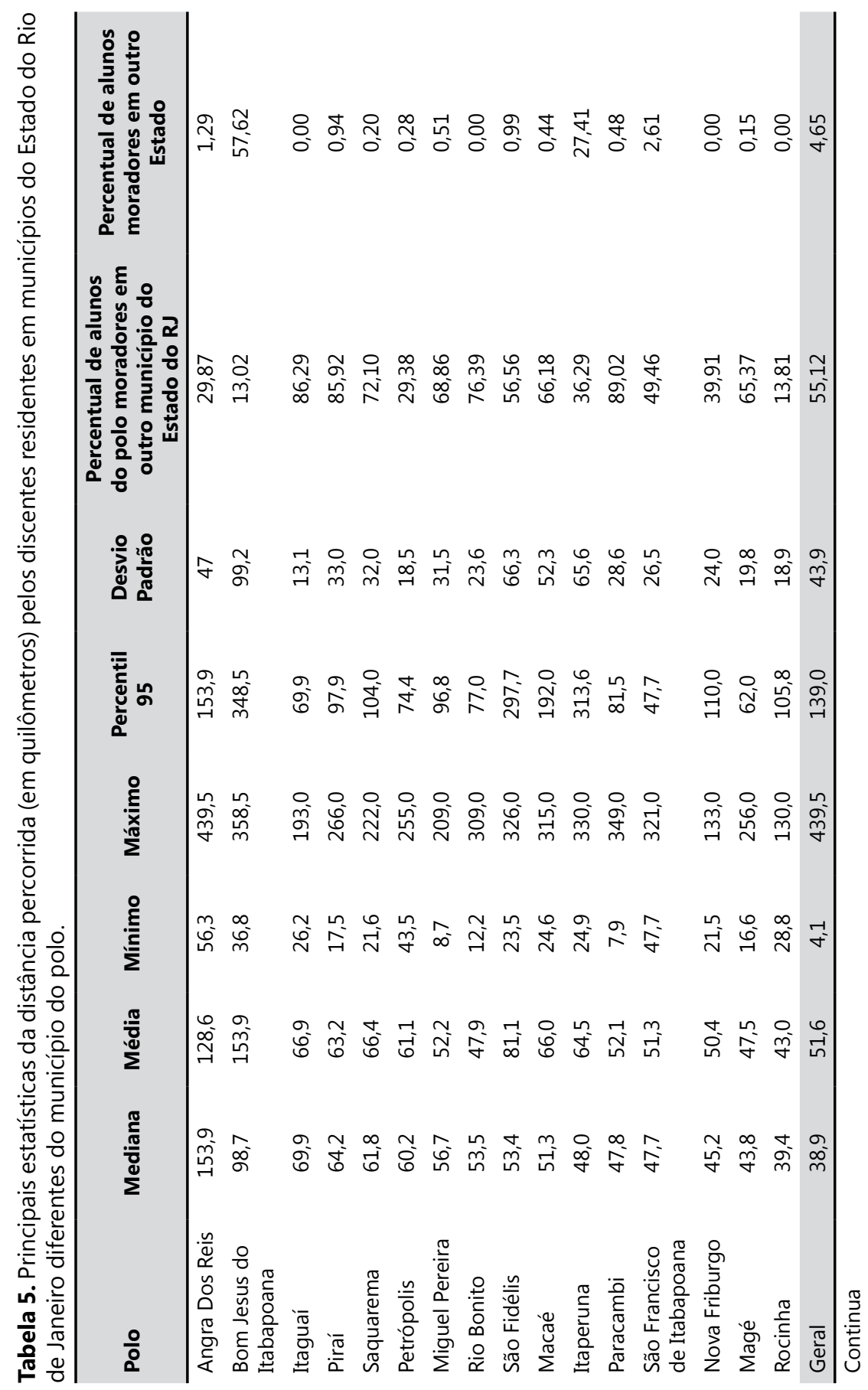




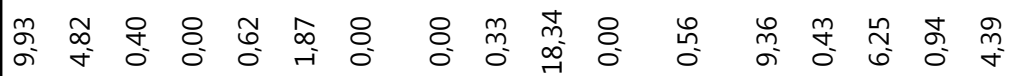

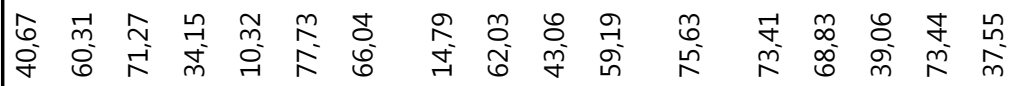

号

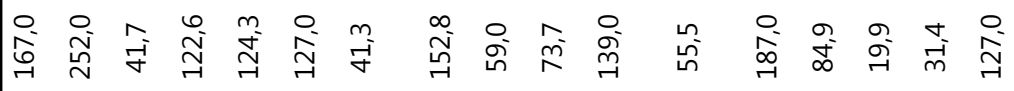

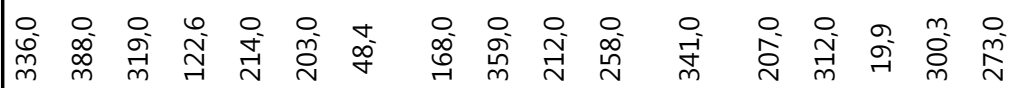

竎

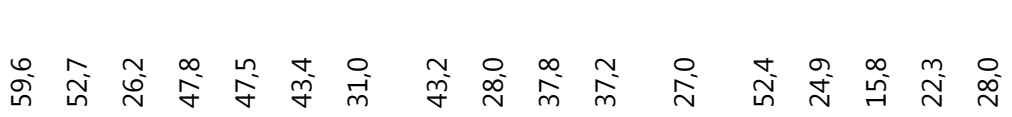

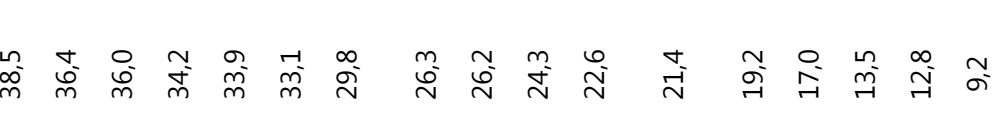

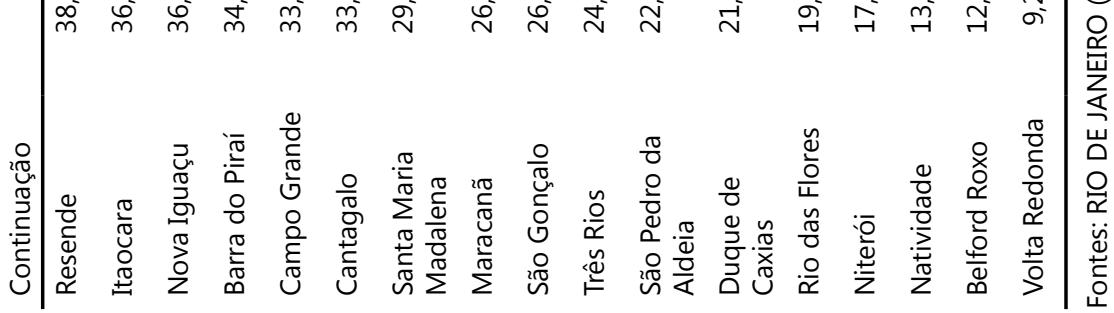


No geral, os alunos ativos que não residem no mesmo município do polo têm que se locomover, em média, 51,6 quilômetros para chegarem ao polo em que estão matriculados. Estima-se que $50 \%$ dos alunos que não moram no mesmo município do polo percorram 38,9 quilômetros ou menos, conforme é exibido pela mediana, e somente $5 \%$ dos alunos percorram uma distância superior a 139,0 quilômetros, conforme mostra o percentil 95. A variabilidade é alta, dada a diversidade de origens dos discentes ativos, e foi medida pelo desvio padrão.

Observa-se que os polos Santa Maria Madalena, Maracanã, São Gonçalo, Três Rios, São Pedro da Aldeia, Duque de Caxias, Rio das Flores, Niterói, Natividade, Belford Roxo e Volta Redonda apresentam as maiores concentrações de alunos que residem próximo aos municípios dos polos. Nestes polos, estima-se que o aluno que mora em outro município, dentro do Estado do Rio de Janeiro, percorra uma distância mediana menor que 30 quilômetros. Os polos que possuem alunos residentes em municípios mais distantes, em termos medianos, são Angra dos Reis, Bom Jesus do Itabapoana, Itaguaí, Piraí, Saquarema e Petrópolis. Para estes polos, a mediana de distância entre o município de residência do aluno e o polo é maior que 60 quilômetros, ou seja, pelo menos $50 \%$ dos alunos que não residem no mesmo município do polo viajam mais de 60 quilômetros para chegarem ao polo onde estão matriculados. Em Angra dos Reis, pelos valores medianos e percentil 95 iguais a 153,9, que é a distância entre Angra dos Reis e Rio de Janeiro, percebemos que pelo menos $45 \%$ dos discentes de Angra dos Reis que residem em outro município podem ser moradores da capital.

Quando avaliamos o percentual de alunos do polo que moram em outro município do Estado do Rio de Janeiro, exibidos também na Tabela 5, observamos que, no geral, $55,12 \%$ dos alunos ativos do Cederj moram em municípios distintos do polo. Os polos com os maiores percentuais de alunos de outros municípios são, nesta ordem, Paracambi, Itaguaí, Piraí, Cantagalo, Rio Bonito e Duque de Caxias, todos com mais de $75 \%$ dos discentes moradores de outros municípios do Estado do Rio de Janeiro. Ao contrário disso, os polos Maracanã, Rocinha, Bom Jesus de Itabapoana e Campo Grande apresentam os menores percentuais de alunos residentes em outros municípios do Estado do Rio de Janeiro. Vale salientar, entretanto, que o polo de Bom Jesus de Itabapoana tem 57,62\% dos alunos residentes fora do Estado do Rio de Janeiro e é o polo que presta mais serviço a estudantes de outro Estado, a saber, o Espírito Santo. Este dado é muito atípico, pois a proporção geral de alunos de outro Estado no Cederj é de apenas 4,65\%, mas justifica-se, uma vez que o município de Bom Jesus de Itabapoana confunde-se com o município de Bom Jesus do Norte, já no Espírito Santo, separados apenas por um rio. 
Sob outro ponto de vista, a Tabela 6 mostra estatísticas da distância percorrida pelos alunos moradores do Estado do Rio de Janeiro - público de interesse principal da instituição - ao polo. Porém, foram incluídos no cálculo os alunos que residem no mesmo município do polo, considerando que percorrem uma distância nula. O valor da média de distância percorrida é um importante parâmetro para avaliar globalmente o polo, uma vez que considera todos os alunos do Estado do Rio de Janeiro, incluindo os que residem no mesmo município do polo em questão.

Tabela 6. Principais estatísticas da distância percorrida pelos alunos moradores do Estado do Rio de Janeiro até o polo, incluindo no cálculo os alunos do mesmo município.

\begin{tabular}{lccccc}
\hline & Média & Mediana & $\begin{array}{c}\text { Percentil } \\
\mathbf{9 5}\end{array}$ & $\begin{array}{c}\text { Desvio } \\
\text { Padrão }\end{array}$ & CV \\
\hline Itaguaí & 57,8 & 69,9 & 69,9 & 26,1 & 0,45 \\
Piraí & 55,9 & 41,7 & 97,9 & 37,1 & 0,66 \\
Saquarema & 47,9 & 51,2 & 104,0 & 40,3 & 0,84 \\
Bom Jesus do & 47,5 & 0,0 & 329,2 & 89,9 & 1,89 \\
Itabapoana & & & & & \\
Paracambi & 46,6 & 47,8 & 81,5 & 31,4 & 0,67 \\
São Fidélis & 46,4 & 53,4 & 156,0 & 64,2 & 1,38 \\
Macaé & 43,9 & 27,8 & 169,0 & 52,8 & 1,20 \\
Rio das Flores & 42,6 & 19,2 & 187,0 & 61,0 & 1,43 \\
Angra Dos Reis & 38,9 & 0,0 & 153,9 & 64,5 & 1,66 \\
Rio Bonito & 36,6 & 29,7 & 77,0 & 29,0 & 0,79 \\
Miguel Pereira & 36,1 & 37,8 & 86,4 & 35,6 & 0,99 \\
Cantagalo & 34,4 & 33,1 & 117,6 & 37,9 & 1,10 \\
Itaocara & 33,4 & 23,7 & 176,0 & 55,9 & 1,67 \\
Itaperuna & 32,3 & 12,5 & 108,0 & 56,5 & 1,75 \\
Magé & 31,4 & 38,4 & 59,6 & 27,7 & 0,88 \\
Geral & 29,9 & 14,8 & 104,0 & 42,1 & 1,4 \\
Resende & 27,0 & 0,0 & 167,0 & 47,4 & 1,76 \\
São Francisco de & 26,0 & 47,7 & 47,7 & 31,9 & 1,22 \\
Itabapoana & & & & & 1,62 \\
São Pedro da Aldeia & 22,1 & 14,8 & 126,1 & 35,9 & 1,36 \\
Duque de Caxias & 20,9 & 21,4 & 48,4 & 28,4 & 0,74 \\
Santa Maria Madalena & 20,5 & 29,8 & 31,6 & 15,1 & 1,44 \\
Nova Friburgo & 20,1 & 0,0 & 76,7 & 29,0 & 1,45 \\
Três Rios & 20,0 & 12,9 & 73,3 & 29,0 & 1,17 \\
Nova Iguaçu & 18,7 & 10,8 & 36,0 & 21,9 & 1,25 \\
São Gonçalo & 18,2 & 12,6 & 47,1 & 22,7 & 1,65 \\
Petrópolis & 18,0 & 0,0 & 64,2 & 29,6 & \\
\hline Continua & & & & & (1, \\
\hline
\end{tabular}

Continua 


\begin{tabular}{lccccc} 
Continuação & \multicolumn{7}{l}{} \\
\hline Niterói & 17,2 & 12,4 & 46,3 & 28,9 & 1,68 \\
Belford Roxo & 16,5 & 12,8 & 31,4 & 20,7 & 1,25 \\
Barra do Piraí & 16,3 & 0,0 & 122,6 & 30,8 & 1,88 \\
Volta Redonda & 11,0 & 0,0 & 49,9 & 26,3 & 2,40 \\
Natividade & 6,6 & 0,0 & 19,9 & 8,1 & 1,23 \\
Maracanã & 6,4 & 0,0 & 29,3 & 21,8 & 3,41 \\
Rocinha & 5,9 & 0,0 & 39,4 & 16,4 & 2,76 \\
Campo Grande & 4,9 & 0,0 & 33,9 & 18,4 & 3,72 \\
\hline
\end{tabular}

Nota: CV: Coeficiente de Variação.

Fontes: RIO DE JANEIRO (2012), Google Maps $^{\circledR}$ (2013).

Os resultados acima mostram que, para os alunos que moram no Estado do Rio de Janeiro, ou seja, considerando o público-alvo principal na construção do Consórcio Cederj, a distância média percorrida pelos alunos é de 29,9 quilômetros, e a mediana é de 14,8 quilômetros, ou seja, pelo menos $50 \%$ percorrem distância menor que 14,8 quilômetros para chegar ao polo. Em nenhum dos polos a média chega a 60 quilômetros. Estes dados são compatíveis com o projeto político e pedagógico do Consórcio Cederj que pretende uma presença dos estudantes nos polos não obrigatória, de uma a duas vezes por semana no primeiro ano, semanal a partir do segundo ano, além das atividades obrigatórias, tais como laboratórios didáticos (para cursos como o de Ciências Biológicas, Física e Química), bem como para a execução das provas presenciais obrigatórias. Desta forma, uma distância excessiva entre a residência do estudante e o polo de apoio presencial poderia contribuir para a evasão dos cursos de graduação na modalidade semipresencial.

Neste sentido, na construção do Consórcio Cederj, o projeto previa um deslocamento médio inferior a 50 quilômetros. De acordo com os dados aqui apresentados, somente as distâncias médias percorridas pelos alunos dos polos de Itaguaí e Piraí ultrapassam esta meta. Considerando a mediana, convém ressaltar também os resultados dos polos de São Fidélis e Saquarema, cujas distâncias ultrapassam 50 quilômetros. No entanto, através do coeficiente de variação, observamos a alta variabilidade da distância percorrida por estes alunos em todos os polos. Esta variabilidade pode ser explicada, em parte, pelo fato de os polos não oferecerem todos os cursos de graduação ativos do Consórcio Cederj. Espera-se, nos próximos anos, que, com o aumento da oferta dos atuais cursos e com a oferta de novos cursos nos polos regionais, a média seja reduzida dentro dos limites estabelecidos e que esta variabilidade diminua. 


\section{Conclusões}

Vários autores problematizam os sentidos dos termos presença e distância na educação (AUTHIER, 1998; LITO, 2010; TORI, 2010; VALLE; BOHADANA, 2011), procurando qualificar uma educação que se diz a distância - EAD - e que, entretanto, está imersa em significações que nos remetem ao estudo colaborativo e à interatividade. Neste trabalho, no entanto, a preocupação com a distância física entre a residência do estudante EAD e o polo de apoio presencial toma uma significação relevante, visto que consideramos, no modelo adotado pelo Cederj, de suma importância que os alunos tenham acesso aos recursos humanos e infraestrutura material disponibilizada neste local $^{4}$.

O Estado do Rio de Janeiro possui 92 municípios, e o Cederj possui polos de apoio presencial em 31 deles. O presente estudo mostra que o Cederj possui alunos ativos em todos os municípios do Estado do Rio de Janeiro, ou seja, que a metodologia de educação a distância adotada no Consórcio efetivamente permite atender à população de todo o Estado do Rio de Janeiro, conforme previsto no projeto original. Também atende o disposto no Plano Estadual de Educação (PEE/RJ de 18 de dezembro de 2009) como área de abrangência de atuação da Fundação (Cecierj) (RIO DE JANEIRO, 2009).

Neste contexto, verificamos que 39,81\% dos discentes ativos, ou seja, 8.638 alunos do Cederj moram no mesmo município do polo em que realizam suas atividades presenciais e 60,19\%, ou seja, 13.061 alunos residem em um município diferente do polo em que estão matriculados. Adicionalmente, existe uma densidade maior de alunos nos 31 municípios com polos (278,65 alunos/município) quando comparado aos 61 municípios sem polos regionais (214,11 alunos/município). Isto é, nos municípios que sediam os polos Cederj temos apenas 30\% a mais de alunos Cederj em relação aos demais, o que indica a distribuição geográfica razoável dos polos Cederj pelo território do Estado. Esta diferença poderia ser reduzida com a implementação de novos cursos em polos estratégicos, e a construção de alguns polos adicionais, por exemplo, em Teresópolis, conforme discutido.

O Cederj foi construído visando complementar a oferta de educação superior presencial, concentrada nos municípios do Rio de Janeiro (UFRJ, UERJ e UNIRIO), vizinhos ao município do Rio de Janeiro (UFF em Niterói e UFRRJ em Seropédica) e em Campos dos Goitacazes (UENF). Quando analisado por mesorregião, o estudo mostra que, de fato, a menor densidade de alunos ativos,

\footnotetext{
4 Ver declarações dos alunos egressos dos cursos oferecidos pelo Consórcio Cederj apresentadas por Granato et al. (2010) e, também, as avaliações institucionais respondidas pelos estudantes e disponibilizadas em www.cederj.edu.br.
} 
em abril de 2012, era a da região metropolitana do Rio de Janeiro (com a maior concentração das universidades públicas presenciais), com apenas 0,82 alunos por 1.000 habitantes, seguido da mesorregião Norte Fluminense, onde se localiza a UENF, em Campos dos Goitacazes, com 1,7 alunos por 1.000 habitantes.

Olhando agora sob a ótica do número relativo de alunos, os maiores índices (IACMH) são nas macrorregiões do Noroeste Fluminense (3,99/1.000 habitantes), do Sul Fluminense (3,82/1.000 habitantes) e do Centro Fluminense (3,77/1.000 habitantes), ou seja, a prioridade de atuação do Cederj são nas regiões distantes da capital e de Campos dos Goytacazes, onde se situam as universidades públicas oferecendo cursos presenciais.

Neste sentido, concluímos que a missão inicial do Cederj, de oferecer ensino público e gratuito em regiões não atendidas, ou pouco atendidas, vem sendo adequadamente implementada.

Quatorze municípios têm uma baixa densidade de alunos no Consórcio Cederj, com índices de números de alunos ativos por 1.000 habitantes inferiores a 1,0. Desses, oito municípios situam-se próximos às universidades públicas presenciais, estando em conformidade com a pretensão do projeto original. Seis municípios apresentam distorções ao projeto original: Teresópolis e Guapimirim (vizinho a Teresópolis) deveriam ser atendidos pelo polo regional de Teresópolis, que não se concretizou, e os municípios de Armação dos Búzios, Itaguaí, Guapimirim e Tanguá, provavelmente, pelo baixo desempenho em termos de número de cursos de graduação nos polos que atendem a estes municípios. 


\title{
Spatial distribution of regional Cederj poles: a statistical analysis
}

\begin{abstract}
This study aims to evaluate the geographical inclusion achieved by the offer of undergraduate distance learning courses by the Cederj Consortium in the State of Rio de Janeiro. Data regarding the number of active students in April 2012 and their home addresses were obtained and analyzed using the program SPSS. Indexes of the number of students attending the program per 1.000 inhabitants (IACMH) or per 1.000 homes (IACMD), at a specific municipal district or State "mesoregion", were calculated based on the data available at IBGE (2010). The distance from each student's residence to the pole - place for "face to face" activities - was estimated through Google Maps. The results indicate that the initial mission of Cederj of offering public and free education in areas where the public universities with conventional courses are absent has been appropriately accomplished.
\end{abstract}

Keywords: Distance education. Democratization of access to higher education. Pole of classroom support.

\section{Distribución espacial de polos regionales Cederj: un análisis estadístico}

\section{Resumen}

Este estudio tiene como objetivo evaluar la cobertura geográfica de los cursos superiores de graduacion por medio de educación a distancia del Consorcio Cederj en el Estado de Rio de Janeiro. Se trata de un estudio censitario, que incluye todos los alumnos en abril de 2012. Se han colectado los datos que se refieren al número de alumnos y sus respectivos locales de residencia que, posteriormente, fueron análisados utilizando el programa SPSS. Se han calculado los índices del número de alumnos para cada 1.000 habitantes (IACMH), y del número de alumnos para cada 1.000 domicilios (IACMD), con base en datos del IBGE en 2010. Los análisis fueron categorizados por municipio y región del estado. La distancia entre residencia y polo, ha sido estimada con recursos del Google Maps. Los resultados obtenidos indican que el Cederj ha realizado a contento su misión de ofrecer enseñanza pública y gratuita en localidades poco o no contempladas por las instituciones públicas de enseñanza superior.

Palabras clave: Educación a distancia. Democratización del acceso a la educación superior. Polo de atendimiento presential. 


\section{Referências}

ALONSO, K. M. A avaliação e a avaliação na educação a distância. In: PRETI, O. (Org.). Educação a distância: sobre discursos e práticas. Brasília, DF: Liber Livro, 2005. p. 153-69.

AUTHIER, M. Apprendre à distance: le monde de l'éducation, de la culture et de la formation. France: [s.n.], 1998. (Hors-série).

BARRETO, C.C. Etapas de produção de material didático impresso para EAD: compartilhando uma experiência. In: BARRETO, C.C. et al. Planejamento e elaboração de material didático impresso para educação a distância. Rio de Janeiro: Fundação CECIERJ, 2009. p. 243-69.

BIELSCHOWSKY, C.E. Educação superior a distância: uma estratégia para avaliação institucional. In: BRASIL. Ministério da Educação e Cultura, Secretaria de Educação a Distância. Desafios da educação a distância na formação de professores. Brasília, DF, 2006. p. 51-65.

FLINTE, V.; GRENHA, V; MACEDO, M.V. Frequência dos alunos nas tutorias presenciais e seu desempenho acadêmico em disciplinas de primeiro período do curso de Licenciatura em Ciências Biológicas, CEDERJ. In: CONGRESSO BRASILEIRO DE EDUCAÇÃO SUPERIOR A DISTÂNCIA, 5., 2008, Gramado, RS. Anais... Disponível em: < http://200.169.53.89/ download/CD\%congressos/2008/VESUD>. Acesso em: maio 2009.

GRANATO, T. M. et al. O destino dos alunos egressos de cursos oferecidos através do Consórcio CEDERJ: relatório de pesquisa de egressos formados 2005-2009. Rio de Janeiro: Fundação CECIERJ/Consórcio CEDERJ, 2010.

INSTITUTO BRASILEIRO DE GEOGRAFIA E ESTATÍSTICA - IBGE. Censo demográfico 2010: resultados do universo. Rio de Janeiro, IBGE, 2010. Disponível em: <http:/www.ibge.gov.br/home/estatistica/populacao/ censo2010/default.shtm>. Acesso em: jan. 2012.

LACERDA, F. K. D. Contribuições da educação a distância para a educação ambiental: utilização da rede sociotécnica na análise das concepções de meio ambiente e saúde no Polo de Nova Friburgo. 2012. 292 f. Tese (Doutorado em Meio Ambiente) - Universidade do Estado do Rio de Janeiro, Rio de Janeiro, 2012.

LITO, F.M. Aprendizagem a distância. São Paulo: Imprensa Oficial do Estado de São Paulo, 2010. 
MEDEIROS, L. et al. Sistemas de tutoria em cursos a distância: programa interinstitucional de capacitação em EAD para a UAB. Brasília, DF: Secretaria de Educação a Distância, 2007.

POLAK, Y. N. S. A avaliação do aprendiz em EAD. In: LITTO, F. M.; FORMIGA, M. M. M. (Org.). Educação a distância: o estado da arte. São Paulo, Pearson Education do Brasil, 2009. p. 153-60.

RIO DE JANEIRO (ESTADO). Consórcio CEDERJ. Projeto político pedagógico. Rio de Janeiro, 2000.

. Consórcio CEDERJ, Diretoria de Registro Escolar. Base de dados. Rio de Janeiro, 2012a.

. Fundação CECIERJ. Polos. Rio de Janeiro, 2012b. Disponível em: $<\mathrm{http} / / /$ cederj.edu.br/cederj/polos/>. Acesso em abr. 2013.

. Lei no 5.597, de 18 de dezembro de 2009. Institui o Plano Estadual de Educação - PEE/RJ, e dá outras providências. Disponível em: $<$ http:/download.rj.gov.br/documentos/10112/448712/DLFE-31621.pdf/ planoestadualdeeducacao.pdf $>$. Acesso em: jan. 2012.

SALGADO, M. U. C. Características de um bom material impresso para a educação a distância. In: ALMEIDA, M. E. B.; MORAN, J. M. (Org.). Integração das tecnologias na educação: salto para o futuro. Brasília, DF: Secretaria de Educação a Distância, 2005. v. 1, p. 154-8.

TORI, R. Educação sem distância: as tecnologias interativas na redução das distâncias em ensino e aprendizagem. São Paulo: Editora Senac, 2010.

VALLE, L.; BOHADANA, E. Sobre presença e distância: reflexões filosóficas sobre a ead online. In: Reunião da Associação Nacional de Pós-Graduação e Pesquisa em Educação - ANPED, 33., 2010. Anais... Rio de Janeiro: ANPED, 2010. Disponível em: $<$ http://33reuniao.anped.org.br/33encontro/app/webroot/ files/file/Trabalhos\%20em\%20PDF/GT17-6042-Int.pdf $>$. Acesso em: jan. 2015. 


\section{Informações dos autores}

Keila Mara Cassiano: Doutorado em Engenharia Elétrica na Área de Métodos de Apoio a Decisão, Pontifícia Universidade Católica do Rio de Janeiro - PUC-Rio. Professora da UFF. Contato: keilamath@hotmail.com

Fátima Kzam Damaceno de Lacerda: Doutorado, UERJ, Programa Multidisciplinar em Meio Ambiente - PPGMA. Professora adjunta da UERJ e coordenadora adjunta da Universidade Aberta do Brasil - UAB/UERJ. Contato: fatima_kzam@yahoo.com.br

Carlos Eduardo Bielschowsky: Doutorado em Física pelo Centro Brasileiro de Pesquisas Físicas. Professor associado da UFRJ. Presidente da Fundação Centro de Ciências e Educação Superior a Distância do Estado do Rio de Janeiro - Fundação CECIERJ de Ciências e Educação. Contato: biel@cecierj.edu.br

Masako Oya Masuda: Pós-doutorado na UCLA - Los Angeles. Vice-presidente do Consórcio CEDERJ. Contato: masako@cecierj.edu.br 